\title{
ELECTRIC RESPONSE OF VISUAL CENTER IN FISH, ESPECIALLY TO COLORED LIGHT FLASH*
}

\author{
JIHEI KONISHI ${ }^{* *}$ \\ Laboratory of Physiology and Ecology, Faculty of Fisheries, \\ Prefectural University of Mie, Japan
}

In response to photic stimulation to the eye the tectum opticum gives rise to the potential change consisting of several components. An analysis of the same in catfish was also made by Buser recently (1955). He observed two slow surface negative components in the response, the $P$ effect and the $T$ effect, and concluded that these represent the post-synaptic components. The present paper concerns the results on this subject, especially on the response to colored light and also their correlation with the peripheral events.

\section{METHOD}

All the experiments were performed during winter season (water temp., $8^{\circ}-12^{\circ} \mathrm{C}$.). The materials used were cruscian carps, Carassius auratus (L.), typifying the diurnal fish, average body length, $10 \mathrm{~cm}$., and adult eels, Anguilla japonica T. et S., as nocturnal fish. The fishes were not usually anesthetized, but in some case the experiment was done under urethane anesthesia. The spinal cord was disected and the brain was carefully exposed, and the vagal lobe was destroyed. In the experiments on the scotopic response, the same procedure was followed under the dim red light after their dark-adaptation more than one hour. As the white light stimulus, the light from the $6 \mathrm{~V}$ headlight bulb, passes through the heat-free filter and the condensing lens, and converges to the eye. Virtually the entire retina was illuminated in all the experiments. The non-illuminated eye was excised. The colored light was obtained by interposition of different color filters across the white light beam from the $200 \mathrm{~W}$ projection lamp. Non-metallic interference filters with the maximum transmission at $470,530,580,610$ and $670 \mathrm{~m} \mu$ were chiefly used. Riken gelatine color filters 66 and 72 , with the maximum transmission at 660 and $720 \mathrm{~m} \mu$, were used only occasionally. The interferences were combined with the gelatine filters to cut out side bands. The colored lights used were

Received for publication July 17, 1959.

* The outline of this paper was presented at the regular meeting of the Japanese Society of Scientific Fisheries held in Nagoya, Sept. 30, 1956 and at the Symposium on Aquatic Animal Physiology, annual meeting of the Japanese Society of Scientific Fisheries, Tokyo, April 3, 1959.

**小推活得得 
mainly adjusted to have the equal efficiency to the stimulation of visual violet of fish and partly adjusted to the equal energy spectrum. For the adjustment in the former, the absorption spectrum of visual violet obtained by Hosoya (1957) in Carassius was adopted. To pick up the central response the leading electrode, consisting of a silver-silver chloride wire, was placed on the surface of the tectum, and the reference electrode was placed on the destroyed vagal lobe. The R. C. amplifier with a time constant of $1 \mathrm{sec}$. and the electromagnetic oscillograph with a $H$-type vibrator were employed.

\section{RESULTS}

\section{Response to white light flash in Carassius}

Photopic respones: In fig. $1, A$ is illustrated a typical photopic response to white light flash (about $1 / 30 \mathrm{sec}$. duration) from the middle part of the surface of tectum opticum contralateral to the illuminated eye. The response was rather small in amplitude. The response was composed of complex potential waves, each with long duration, beginning with a surface positive deflection having a latency of 40 to $50 \mathrm{msec}$. in winter season. The on-response might consist of two constituent components, the long-lasting surface negative components and relatively rapid successive ripples with positive electric sign superimposed upon the former potentials, occurring at about $14 \mathrm{msec}$. intervals. Generally there appeared 8 ripples, and these wavelets were numbered as shown in fig. $1, A$ and $B$. Mean latency of each ripple and the fiducial interval are shown in fig. 2. In photopic condition, spontaneous activities were usually observed, and a light flash induced two sequences of surface negative components, a relatively sharp potential and a delayed long-lasting one. Tentatively they will be denoted by the first (PSP 1) and the second surface negative components (PSP 2) respectively. These components may correspond to the " $P$

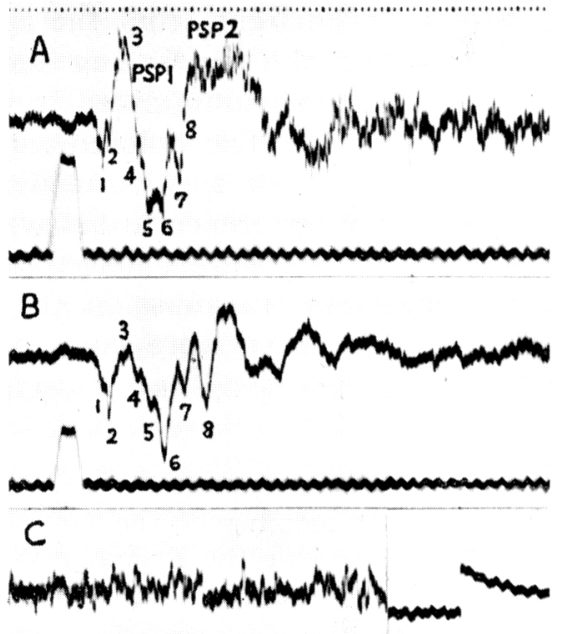

FIG. 1. $A$, typical response to white light flash in photopic Carassius. $B$, an example of the response, showing less prominent surface negative components, but positive ripples are clearly visible. $C$, spontaneous discharge. Negativity upward. Time mark 1/120 sec. Voltage calibration $30 \mu \mathrm{V}$. 


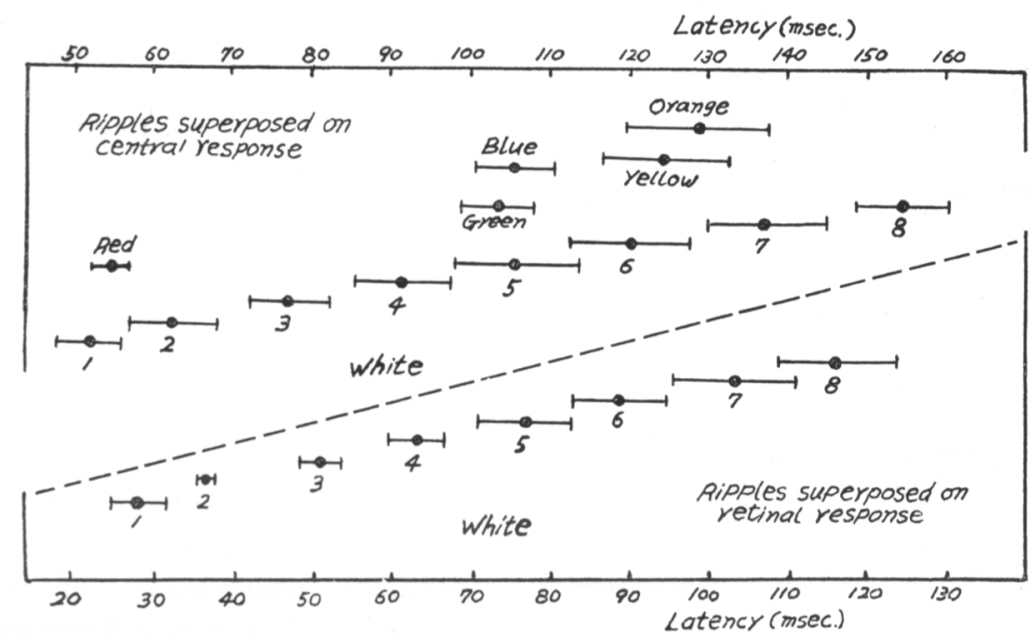

FIG. 2. Mean latency of each ripple superposed on the central and retinal responses. Fiducial interval of the mean $( \pm u \sqrt{F / N})$ is indicated by horizontal lines. $u$ : Standard deviation. $F$ : Variance ratio. $N$ : Number of material. $1-\alpha=0.95$.

effect" and the " $T$ effect", which were observed by Buser (1955) in catfish. The PSP 2 was not the off-response, because of appearance even in prolonged flash (fig. 3). The off-response can hardly be seen so far as the present record is concerned, excepting the record in fig. $3, A$. The surface negative components were abolished abruptly by the local application of procaine, whereas the positive ripples were virtually unaffected. When a microelectrode

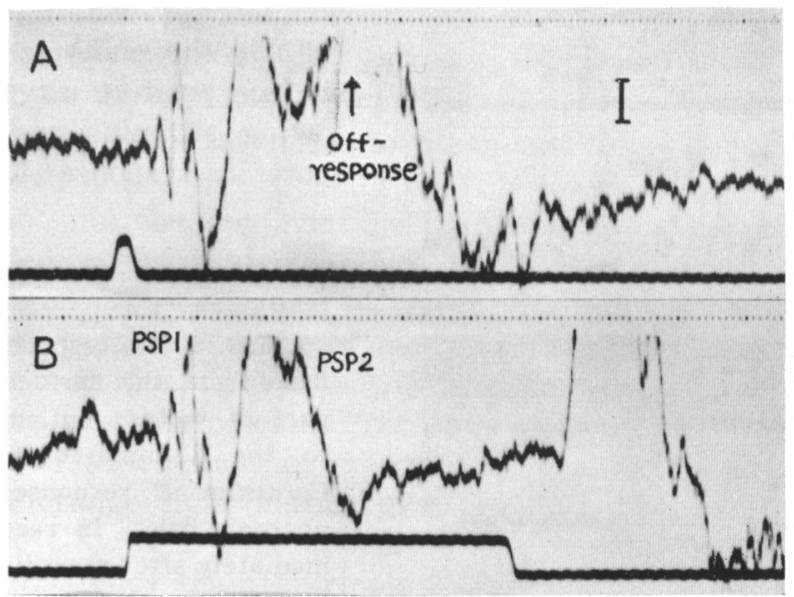

FIG. 3. Comparison between the responses evoked by white light flash with short $(A)$ and long $(B)$ durations. Time mark $1 / 120$ sec. Voltage calibration $30 \mu \mathrm{V}$. 

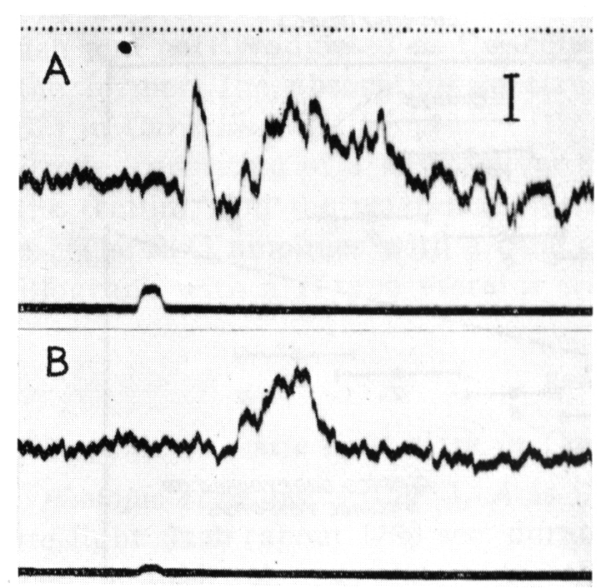

FIG. 4. Comparison between the responses to white light flash with high $(A)$ and low $(B)$ intensities. Time mark $1 / 120$ sec. Voltage calibration $30 \mu \mathrm{V}$.

was inserted into the tectum, the negative components showed an inversion of polarity at a certain depth of the tectum. These facts suggest that the surface negative components are of post-synaptic origin, and is confirmed from Buser's results. Superficial application of nicotine caused the gradual diminution of the surface negative components, but in the process of nicotinization the lengthening of time course of the potentials was temporarily seen before the synapses are blocked.

Records in fig. 4 show a comparison of the responses to high and low intensities of stimulus. For low intensity, a series of the positive ripples following probably the ripple 5 and only the PSP 2 appeared.

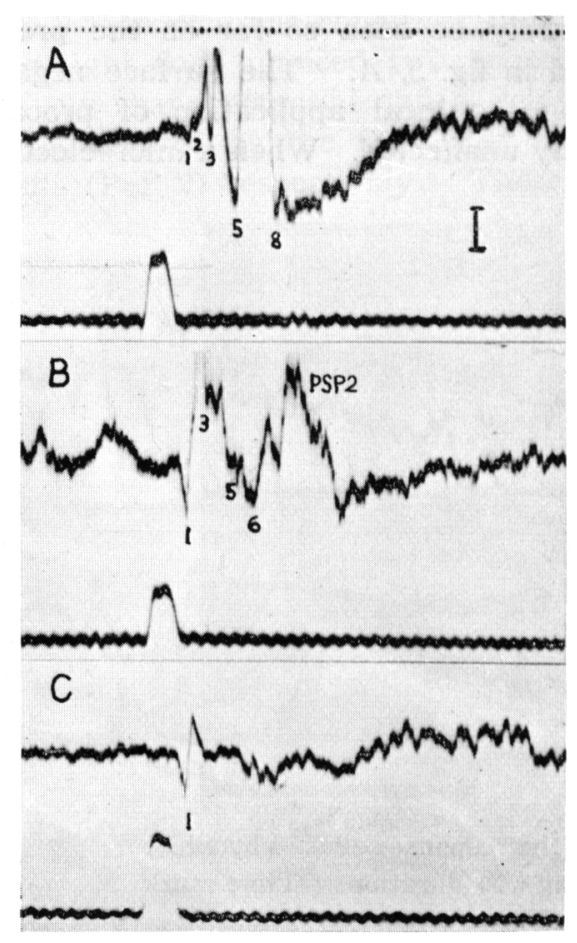

Scotopic response: Responses in scotopic fish to the same stimulus markedly differ from that of photopic condition as illustrated in fig. 5 . The latency of the scotopic response was slightly, about 15 msec., longer than in the photopic one. The first surface positive wave (ripple 1) following stimulus and the PSP 1 in scotopic response were ordinarily

FIG. 5. $A$, response to white light flash from the surface of the middle part of tectum opticum contralateral to the illuminated eye in scotopic Carassius. $B$, response taken from the photopic fish. In record $C$ taken immediately after recording trace $A$, note that latency decreases and gets coincident with that of the response from the photopic fish. Time mark 1/120 sec. Voltage calibration $30 \mu \mathrm{V}$. 
smaller in amplitude than that of photopic fish. The PSP 2 was never observed in the scotopic response. Comparison of the responses of the scotopic and photopic fishes revealed immediately that the positive wave, corresponding to the ripple 5, was pronounced in the former response, and was immediately followed by the large sharp negative deflection. The record $C$ in fig. 5 taken immediately after recording the curve $A$, shows the increasing of the amplitude of the ripple 1 and the shortening of latency which is almost the same magnitude as the response in photopic condition.

\section{Photopic response to colored light flash}

The response to colored light flash in catfish was observed recently by Buser (1955). In his observation, however, characteristic differences among the responses to various colored lights do not seem to be so definite. This may be attributed to the less-development of the visual ability of catfish, especially the color vision.

The results on Carassizis showed obvious differences of the response in time character of each component with respect to wave-length, and again the differences were found to be almost independent of the intensity of concerned light (fig. 6). The response latency to red light flash was the same as to white light flash. The characteristic of the response was the appearance of a large long-lasting post-synaptic component, following the first positive ripple, in which the inconspicuous ripples $3,4,5,6$ and 7 were superposed on it. The ripple 8 appeared at the bottom of the positive deflection immediately following the negative deflection, and a series of successive positive ripples followed. The PSP 2 was never observed in photopic condition as in the case of the scotopic response to white light flash. Notwithstanding, in the present case, each total amount of the energy emitted through red filters was smaller than that of white light, the response was usually larger than the latter response in amplitude. Furthermore, the response having a similar amplitude was caused even by the red light through the Riken color filter 72 which scarcely stimulates the scotopic system (fig. 6, I, D).

An example of typical responses to green and blue light flashes is represented in fig. 6, II, $D$ and $E$. Usually no PSP 1 was observed in response to green light flash, and the dominant positive deflection, corresponding to the ripple 5 , preceded to the post-synaptic potential, on which the inconspicuous ripple 6 superposed. The response to blue light could hardly be distinguished from that to green light in spite of many trials. The characteristic of the response to green or blue light was the pronounced occurrence of the ripple 5 among a series of the ripples. Preceding the ripple 5 ordinarily, a small negative deflection which was not preceded by positive ripple was seen.

Yellow and orange light flashes gave another type of response patterns (fig. 6, II, $B$ and $C$ ). The first appearing positive deflection seemed to have no doubt shorter latency than the ripple 5's, although it could not be identified which ripple corresponds to it, and was succeeded by the pronounced ripple 6 (or 7 ) and the post-synaptic potential. It was also imposible to distinguish clear differences between the responses to yellow and orange light flashes. 


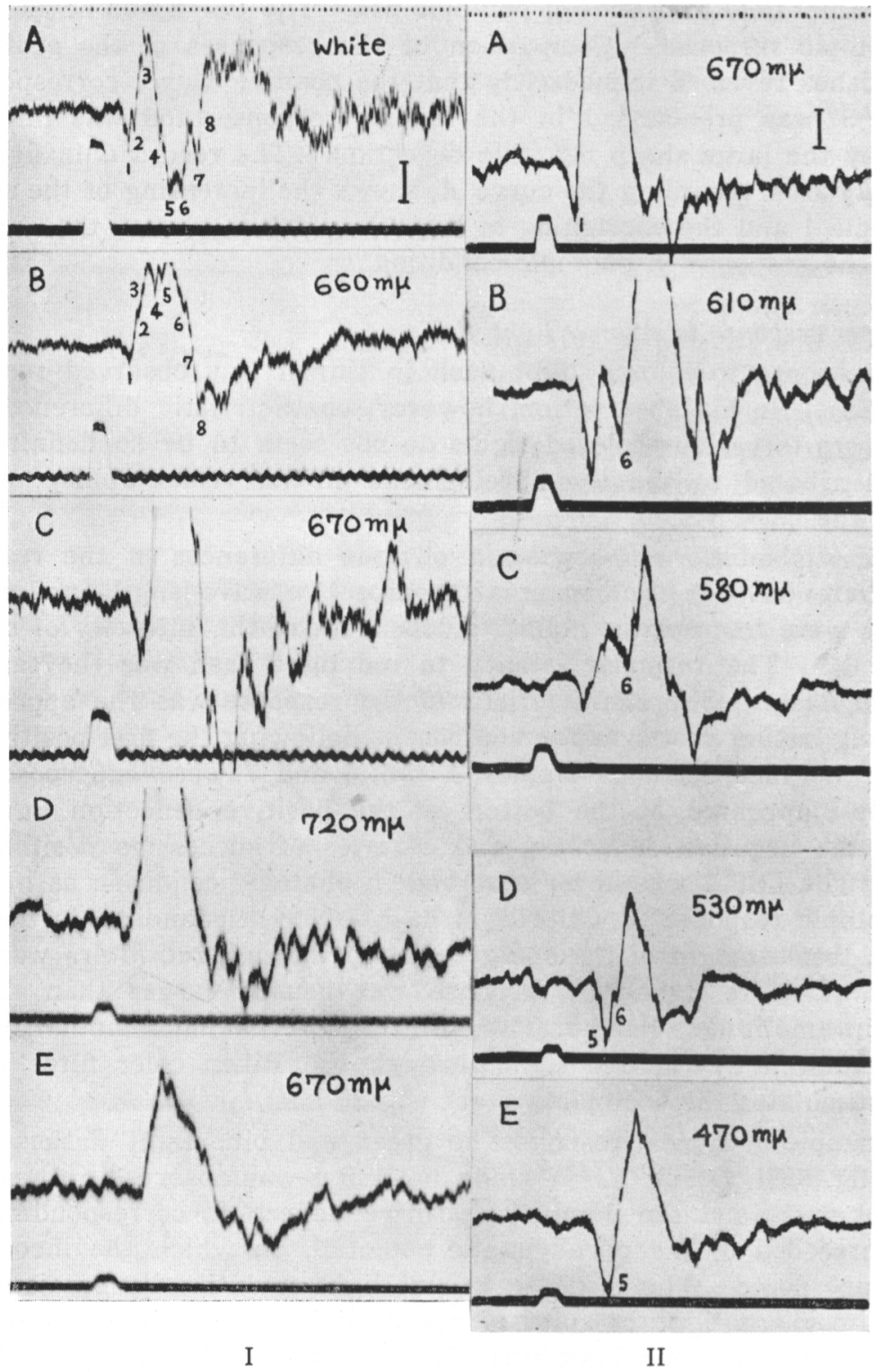

FIG. 6. Series of records in I showing the responses in photopic Carassius to various red light flashes with different wave-lengths. Series of records in II showing effects of colored lights with different wave-lengths. Equal visual violet stimulation is made, excepting record $E$ in I which is obtained by the flash having equal energy spectrum to green light. Time mark $1 / 120 \mathrm{sec}$. Voltage calibration $30 \mu \mathrm{V}$. 


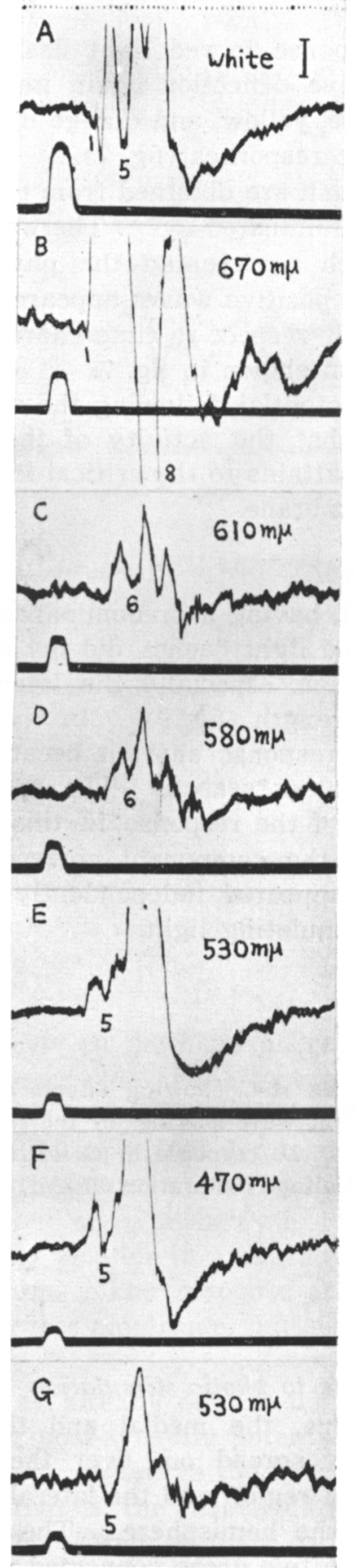

FIG. 7

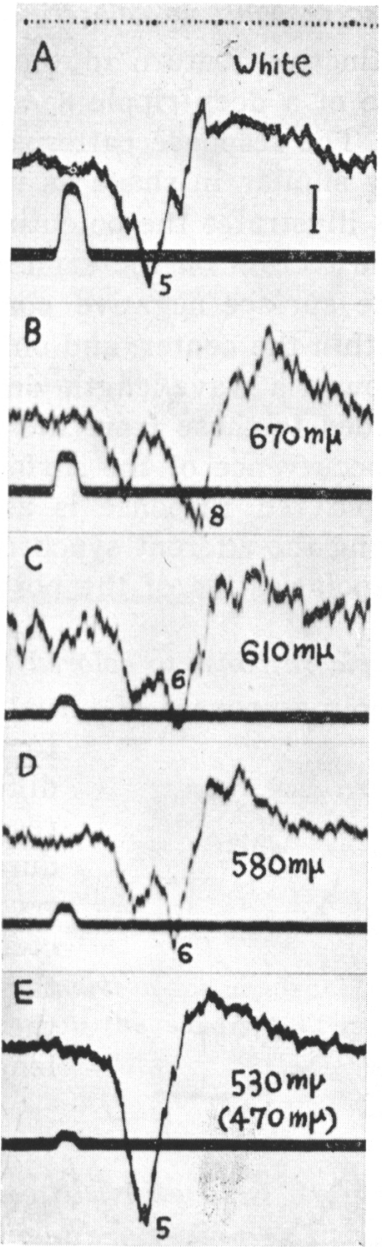

FIG. 8

FIG. 7. Effects of colored lights with different wave-lengths on the response in scotopic Carassius. Time mark $1 / 120$ sec. Voltage calibration $30 \mu \mathrm{V}$.

FIG. 8. Surface positive potentials recorded from the tectum on the same side as the illuminated eye. Time mark $1 / 120$ sec. Voltage calibration $30 \mu \mathrm{V}$. 
Scotopic response to colored light

A distinctive feature in the scotopic response to red light flash was the occurrence of a deep ripple 8, and the negative deflection again immediately followed. The response patterns to green, blue, yellow, and orange lights were essentially similar in shape as in the photopic responses (fig. 7).

Fig. 8 illustrates the potential changes which are obtained from the middle part of the tectum on the same side as the illuminated eye. There never appeared the surface negative component which represented the physiological events within the center, and only the surface positive waves appeared. These waves showed a wave-length dependence with respect to time character, and corresponded to those from the excited tectum shown in fig. 7 .

The occurrence of the surface negative potential following the ripple 8 in the scotopic red response is assignable to that the activity of the ripple 8 , representing the afferent synchronized volley, attains to the critical level which causes depolarization of the post-synaptic membrane.

Photopic response to colored light flash in eel

Photopic responses of visual center in eel, having a predominance of rods, to various colored light flashes did not show any

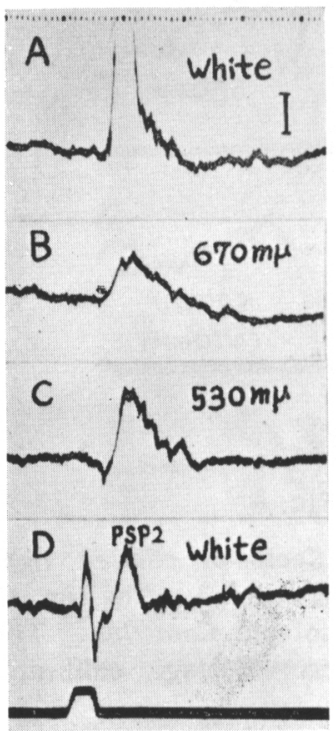
differences in shape, especially the latency, with respect to wave-length (fig. 9). In the records, duration of the response shorten because of the recording in summer season. The most characteristic feature of the response in this fish lack the PSP 1, and the component corresponded to the PSP 2 only appeared independently to wavelength of the stimulating light.

FIG. 9. Records $A-C$ showing effects of colored lights with different wave-lengths on the response in photopic Anguilla. D: response in Carassius. Time mark $1 / 120$ sec. Voltage calibration $30 \mu \mathrm{V}$.

\section{Regional difference of visual center response to photic stimulation}

The optic tract divides into two divisions, the medial and the lateral rami, before entering the tectum, and they spread out over the different restricted regions - the medial ramus to dorsal region and the lateral ramus to caudo-lateral region of the dorsal aspect of the hemisphere. The boundary determined electrophysiologically between the two areas connected with each ramus was considerably sharp. The responses, moreover, varied in shape with 


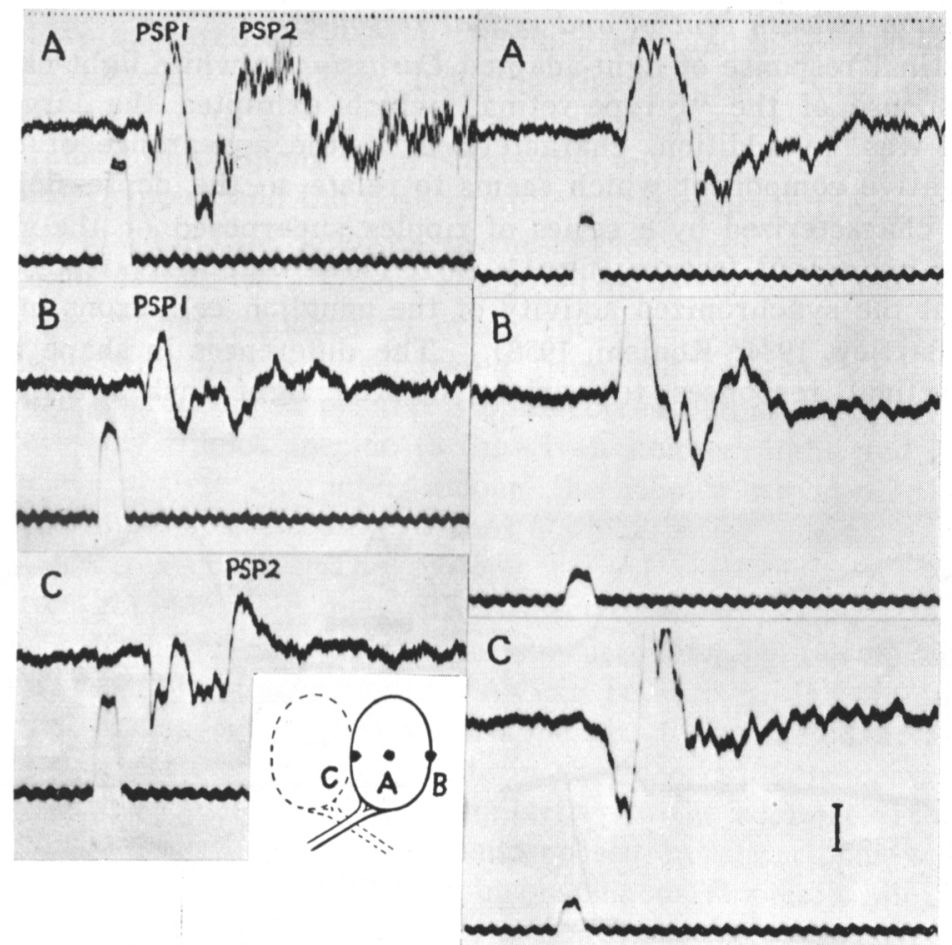

FIG. 10. Responses recorded from different parts of the hemisphere of the tectum, in photopic Carassius as shown in the scheme. Time mark $1 / 120$ sec. Voltage calibration $30 \mu \mathrm{V}$.

different parts on the hemisphere. The response to white light flash recorded from the inner side of the tectum consisted of the successive positive phases and the PSP 2 (fig. 10, $C$ (left column)), while the response from the outer side the PSP 1 appeared dominantly (fig. 10, $B$ (left column)). Both of these responses, therefore, appeared to show the pattern of potential change of opposite electric sign, probably excepting the positive ripples. These responses were usually smaller in amplitude comparing with that from the middle part of the tectum. The response from the middle part of the tectum not only had the largest amplitude, but seemed to consist of both components from the each side.

Then, as already described, the response to red light flash had a large long-lasting post-synaptic potential. However, it was found that the potential was further analysed to the early and the later components by the regional recording, that is, the response to red light from the middle part of the tectum might be composed of these two components with different time character (fig. 10 (right column)). 


\section{Correlation between central and retinal responses}

The retinal response of light-adapted Carassius to white light flash showed typical response of the "I type retina" which exhibited the large $a$-and $b$ waves, and was, in addition, characterized by the appearance of the second cornea negative component which seems to relate to the depression of the $b$ wave, and characterized by a series of ripples superposed on the slow waves as its more prominent feature (fig. $11, D$ ). These oscillatory ripples appeared to represent the synchronized activity of the ganglion cell axons in the retina (Fry and Bartley, 1934; Konishi, 1958). The differences in shape among the photopic retinal responses to various colored light flashes are illustrated

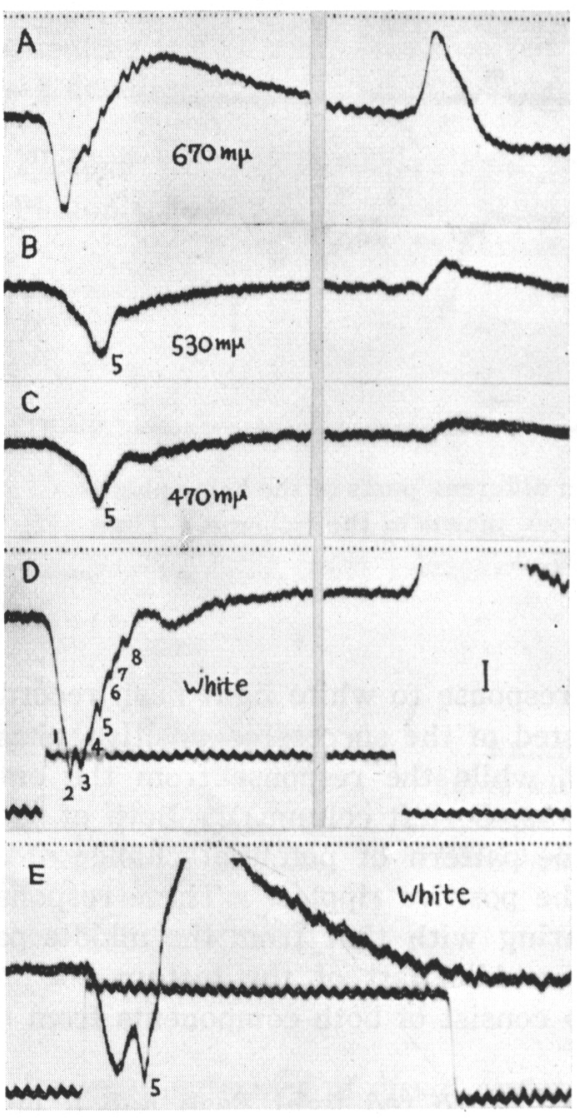

FIG. 11

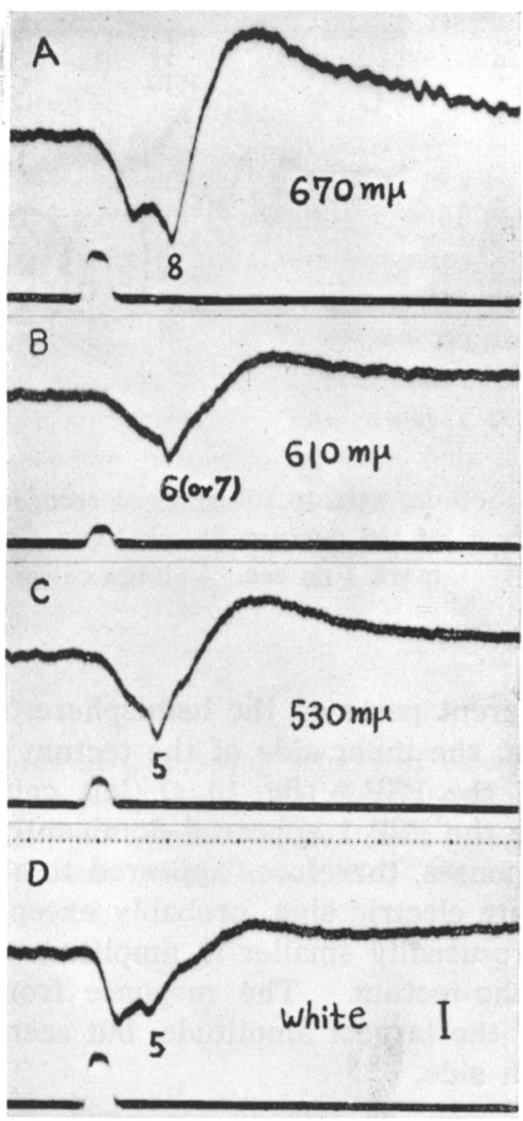

FIG. 12

FIG. 11. $A-D$, retinal responses to spectral lights in photopic eye of Carassius. $E$, retinal response in the scotopic eye. Time mark $1 / 120 \mathrm{sec}$. Voltage calibration $30 \mu \mathrm{V}$.

FIG. 12. Retinal responses to spectral lights in scotopic eye of Carassius. Time mark $1 / 120$ sec. Voltage calibration $30 \mu \mathrm{V}$. 
in fig. 11. With red light flash which should stimulate mainly the photopic system, there appeared the $b$-wave; while green and blue flashes should stimulate the scotopic one, never inducing the $b$-wave. Now, comparing the central responses with the retinal responses to various colored light flashes, the close relationship among them is expected with respect to the occurrence of the oscillatory ripples and the post-synaptic components in the central response. The number and the time intervals of the ripples superposed on both responses to white light flashes were almost equal. This is shown in fig. 2 . On the $a$ wave of the retinal response to green (or blue light) was superposed the ripple 5, another component separated from the $a$-wave, while the central response had a pronounced positive ripple, corresponding to the ripple 5 . The occurrence of the ripples specific to the given colored light and also the correspondencies in time character among the ripples superposed on both of retinal and central responses were shown much more clearly in the records of the scotopic responses. The scotopic retinal response to white light flash differed from the photopic one with respect to the appearance of the $b$-wave and the lack of the off-effect, and was characterized by the feature that the ripple 5 was selectively pronounced. As can be seen in fig. $12, C$ the ripple 5 in the retinal response to green light appeared to be added as a component separate from the slow potential, while in the records of the central responses in fig. $7, E, G$, the ripple 5 appeared similarly. In the scotopic retinal response to red light flash, slow potential was superposed by the ripple which corresponded to the 8 besides the preceded inconspicuous ripples, while in the central response the corresponded ripples followed by the negative components were observed as above presented.

As described above, with white light flash the $b$-wave was hardly elicited in the photopic eye, but the PSP 2 of the central response appeared. On the contrary, red flash caused the $b$-wave in the retinal response, and no PSP 2 in the central response. This may be similar relation as the scotopic responses to white light flash. These facts results in presuming of the possible correlation between the initiation of the PSP 2 in the central response and the depression of the $b$-wave of the retinal response.

\section{Optic nerve discharge}

Typical records of the optic nerve discharges are represented in fig. 13. The optic nerve response to photic stimulus showed rhythmic discharges as observed by Adrian and Matthews $(1927 ; 1928)$ in eel's optic nerve. Each oscillatory ripple of the optic nerve response was found to correspond to those in both of central and retinal responses, though the time course of the former lengthened probably owing to aging preparation. The optic nerve response to green light flash began evidently from the wave, corresponding to the ripple 5 .

Furthermore, it was observed that the discharge was completely inhibited following the ripple 8 in response to white light flash, whereas the inhibition was never induced from that phase by red light flash, but was slightly seen immediately after the ripple 3 . 


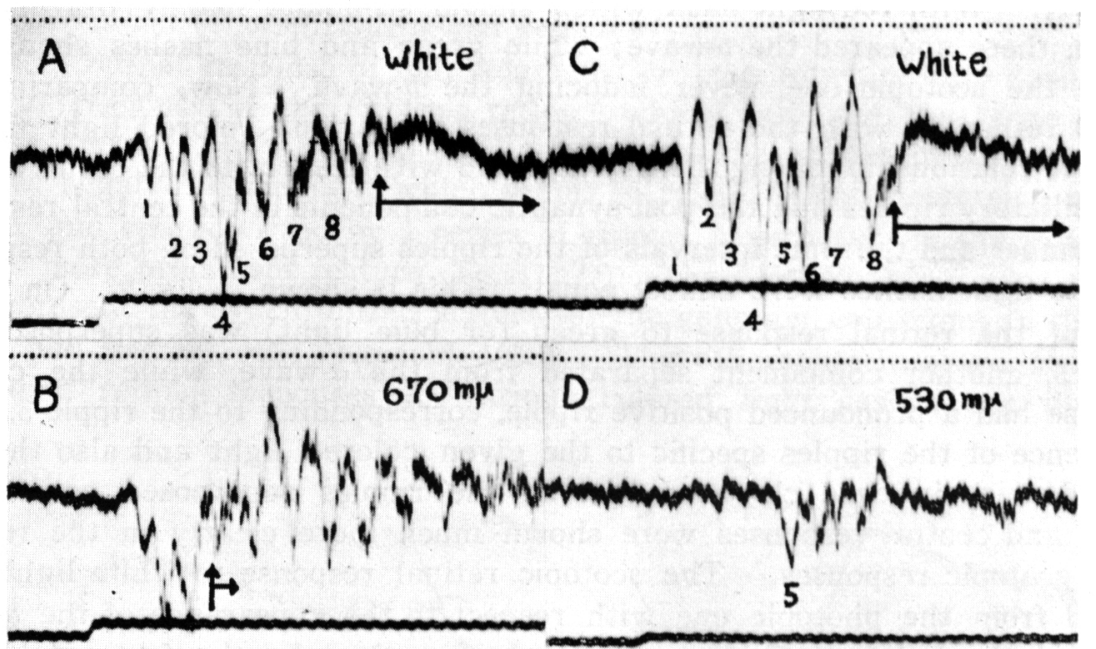

FIG. 13. Optic nerve responses in photopic Carassius. Arrows indicate inhibition of the nervous discharges. Time mark $1 / 120 \mathrm{sec}$.

DISCUSSION

It was shown by the present experiments that the ripples superposed on the central response not only corresponded with each ripple, as was found in the retinal response, representing the synchronous activity in the ganglion cell axons in the retina, but also with each one of the optic nerve discharge, and was also shown that the color specific sensitivity might be revealed by the difference in time character of these nervous activities. The latter results ap. peared to be the similar ones as Donner's (1950), Motokawa's (1949), Goto and Toida's (1954). The fact that the positive ripples in the central response can be recorded almost anywhere on the brain suggests the ripples superposed on the visual center response to be the potential change of an electrical field set up by the synchronous volley of impulses passing along the optic tract. Sometimes no positive potential which should precede to the post-synaptic component, was observed. This is because it was concealed by the dominant latter component, and this was confirmed by the procaine treatment. With a brief flash, as is shown in fig. 1, $A$ the burst of spike potential is frequently observed from the later phase of the PSP 2. This occasion may be attributed to the desynchronization in optic nerve discharge caused by the cessation of illumination, since the same activity is detectable in the level of the optic tract as well. The fact that the ripple 5 was selectively pronounced in the scotopic central response to white light flash strongly suggests that in scotopic condition the excitability of the characteristic element for the green is enhanced in spite of white light flash. This was also shown clearly in Granit's results (1941) in carp. The components which appear in the early phase of the central response may show spectral sensitivity characteristics which identify it as photopic in nature, because of no appearances of the positive ripples in the 
early phase and also the PSP 1 in the response to white light with low intensity and to green or blue light. This is further fortified by the results in eel, having a predominance of rods, in which the response consists of the PSP 2 only and does not shift in shape with respect to wave-length. However, it may be overhasty to conclude that the PSP 2 is regarded to be dependent on the excitation of the rod system itself.

A tentative hypothesis about the initiation of the PSP 2 is considered above to be in relation to the depression of the $b$-wave. Furthermore, in the record of the optic nerve response to white light flash in photopic condition, the inhibition of the discharge is clearly seen from the phase corresponding to the depression of the $b$-wave, whereas the red light flash, contrary, does not cause the inhibition. In view of these facts, it seems probable that the generation of the PSP 2 relates closely to the abrupt depression of the afferent volley of the optic nerve. The results of regional differences of the central response presented above, in which the PSP 2 was evoked dominantly at the dorsal region, and the PSP 1 at the caudo-lateral region, immediately suggest that the neurons within the dorsal region may be inhibited in activity while the afferent fibers are firing, and may be excited in response to the pause of the impulses, and neurons within caudo-lateral region may be excited in the reverse manner. Then, from the regional difference in the red response, the similar relation should be expected. Actually, the temporary inhibition of the synchronous afferent impulses of the optic fibers is noted at the phase which corresponds to the later half of the post-synaptic component in the red response (fig. $13, B$ ).

\section{SUMMARY}

The visual center responses to light flash, especially variable with respect to color, were recorded from the tectum opticum contralateral to the illuminated eye in two fresh water fishes, Carassius auratus (L.) and Anguilla japonica $\mathrm{T}$. et $\mathrm{S}$.

1) The photopic response in Carassius to white light flash consisted of two components, a series of spike potential with positive electric sign which represent the potential changes caused by the synchronous volley of nerve impulses passing along the optic tract, and the slow long-lasting negative components (PSP 1, PSP2) which represent the post-synaptic potential. As the characteristics of the response in the dark-adapted fish, the ripple 5 was pronounced and was immediately followed by the sharp negative component, and the PSP 2 did not appear. The response of the photopic Anguilla to the same flash may consist of the PSP 2 only.

2) The pattern of the response in Carassius differs according to the wavelength of the stimulating light but is independent of the intensity of the light, showing the selective appearance of the ripples followed by the post-synaptic components in response to the concerned colored light; whereas no characteristic differences among the responses to various colored lights were observed in Anguilla, revealing the PSP 2 only in response to any colored light.

3) The pattern of the response from the middle part of the tectum in 
Carassius shows maximal amplitude and appears to be summation of the potential changes from both of inner and outer sides of the tectum of the dorsal aspect of the hemisphere. This was observed in the response to white light flash and also red.

4) The retinal responses and the action potentials of the optic tract in response to white and various colored light flashes were recorded, and were considered with respect to the correlation to the central responses.

5) The possible correlation between the generation of the second surface negative component in the central response (PSP 2) and the abrupt inhibition of the afferent volley of optic nerve impulses was suggested.

The author's many and hearty thanks are due to Prof. N. Y. Kawamoto for his valuable criticism and advices, and especially to Prof. T. Hanaoka, Laboratory of Physiology, Institute of Health, Nara Women's University for his helpful advices.

\section{REFERENCES}

1. Adrian, E. D. And Matthews, R. J. Physiol. 63: 378, 1927.

2. Adrian, E. D. AND Matthews, R. ibid. 65: 273, 1928.

3. AdrIAN, E. D. ibid. 104: 84, 1945.

4. ADRIAN, E. D. ibid. 105: 24, 1946.

5. Armington, J. C., Johnson, E. P. And Riggs, L. A. ibid. 118: 289, 1952.

6. Brown, M. E. The Physiology of Fishes. Vol. 2, New York: Academic Press Inc., 1957.

7. Buser, P. Analyse des Réponses Électriques du Lobe Optique a la Stimulation de la Voie Visuelle chez Quelques Vertébrés Inférieurs. Thèse présentées a la Faculté des Sciences de L'Université de Paris. Masson, Paris, 1955

8. CAJAL, S. R. Histologie du Systeme nerveux de l'Homme et des Vertebrés. Maloine, Paris, Vol. 2: 196, 1911.

9. Donner, K. O. Acta Physiol. Scand. 21: Suppl. 72: 1, 1950.

10. Fry, G. A. And Bartley, S. H. J. Cell. Comp. Physiol. 5: 291, 1934.

11. Goto, M. ANd ToidA, N. Jap. J. Physiol. 4: 123, 1954.

12. Goto, M. AND TOIDA, N. ibid. 4: 221, 1954.

13. Granit, R. Acta Physiol. Scand. 2: 334, 1941.

14. Granit, R. Sensory Mechanisms of the Retina. London: Oxford Univ. Press, 1947.

15. Granit, R. Proc. Roy, Soc. Lond., B, 140: 191, 1952.

16. Granit, R. Receptors and Sensory Perception. New Haven: Yale Univ. Press, 1955.

17. Hosoy A, Y. J. Physiol. Soc. Jap. 19: 673, 1957 (in Japanese).

18. Konishi, J. Zool. Mag. 66: 428, 1957 (in Japanese)

19. KoNISHI, J. ibid. 66: 435, 1957 (in Japanese).

20. KoNISHI, J. ibid. 67: 88, 1958 (in Japanese).

21. KRAUSE, R. Mikroskopische der Wirbeltiere in Einzeldarstellungen. IV. Teleosticr, Plagiostomen, Zyklostomen und Leptokardier. Berlin und Leipzig, 1923.

22. Lennox, M. A. And Madsen, A. J. Neurophysiol. 18: 412, 1955.

23. LenNoX, M. A. ibid. 19: 271, 1956.

24. Madsen, A. ANd Lennox, M. A. ibid. 18: 574, 1955.

25. Mitarai, G. And Yagasaki, Y. Ann. Rep. Resear. Inst. Env. Med. Nagoya Univ. 7 : 113,1955 (in Japanese).

26. MотоKAWA, K. Kagaku 18: 526, 1948 (in Japanese).

27. MotokAwA, K. J. Neurophysiol. 12: 291, 1949. 
28. Svaetichin, G. Acta Physiol. Scand. 29: Suppl. 106: 565, 1953.

29. Svaetichin, G. ibid. 29: Suppl. 106: 601, 1953.

30. Svaetichin, G. ibid. 39: Suppl. 134: 17, 1956.

31. Svaetichin, G. ibid. 39: Suppl. 134: 55, 1956.

32. Svaetichin, G. ibid. 39: Suppl. 134: 67, 1956.

33. TAKATUZI, M. Kaibogaku Zass. 14: 1, 1939 (in Japanese).

34. Toida, N. And Goto, M. Jap. J. Physiol. 4: 260, 1954.

35. TomitA, T. ibid. 1: 110, 1950.

36. Wang, G. H. Chin. J. Physiol. 8: 121, 1934. 